\title{
High risk of hip dislocation following polyethylene liner exchange in total hip arthroplasty-is cup revision necessary?
}

\author{
D. Dammerer ${ }^{1}$ (I) $\cdot$ F. Schneider ${ }^{2} \cdot$ T. Renkawitz $^{3} \cdot$ D. Putzer ${ }^{4} \cdot$ M. Bogensperger $^{1} \cdot$ R. Biedermann $^{1}$
}

Received: 25 May 2020 / Accepted: 9 September 2020 / Published online: 19 September 2020

(c) The Author(s) 2020

\begin{abstract}
Purpose Polyethylene (PE) wear remains a common reason for revision surgery following total hip arthroplasty (THA). An established treatment method is isolated liner exchange in a well-fixed acetabular cup and entails a known high risk of hip dislocation after revision surgery. The purpose of this retrospective study was to determine the rate of hip dislocation after liner exchange.

Methods Patients were included if (1) the PE liner was removable, (2) the acetabular shell was stable with acceptable orientation, (3) no osteolysis around the acetabular cup was found and (4) no dislocation of the THA occurred before revision surgery. We reviewed medical histories and performed radiological measurements using Einzel-Bild-Röntgen-Analyse (EBRA) software. EBRA measurements and statistical investigations were performed by two independent investigators.

Results A total of 82 patients were included in our study. Mean follow-up was six (range: 3.6-9.9) years. In 13 (15.8\%) patients THA dislocations occurred at a mean postoperative period of 20.2 (range: 1-44) weeks after revising the PE liner. This is equivalent to an absolute risk increase of $16 \%$ after revision surgery, which results in a number needed to harm of 6 . This means that every sixth patient with isolated liner exchange can expect to experience dislocation due to wear.

Conclusion In conclusion, isolated exchange of the polyethylene liner because of wear showed a high risk of dislocation and further cup revision. Our results suggest that the threshold for revising well-fixed components in the case of liner wear should be lowered.
\end{abstract}

Trial Registration number and date of registration Number: 20140710-1012 and Date: 2016-03-09.

Keywords Liner exchange $\cdot$ Polyethylene wear $\cdot$ Revision arthroplasty $\cdot$ Dislocation $\cdot$ EBRA

D. Dammerer and F. Schneider contributed equaly.

D. Dammerer

dietmar.dammerer@tirol-kliniken.at

1 Department of Orthopaedics and Traumatology, Medical University of Innsbruck, Anichstrasse 35, 6020 Innsbruck, Austria

2 Department for Trauma Surgery and Sports Medicine, Medical University of Innsbruck, Anichstrasse 35, 6020 Innsbruck, Austria

3 Department of Orthopedic Surgery, Regensburg University Medical Center, Kaiser Karl V.-Allee 3, 93077 Bad Abbach, Germany

4 Department of Experimental Orthopedics, Medical University of Innsbruck, Sonnenburgstrasse 16, 6020 Innsbruck, Austria

\section{Introduction}

Polyethylene (PE) wear remains a common reason for revision surgery following total hip arthroplasty (THA) $[1,2]$. The results of different arthroplasty registers show that replacing a PE liner because of wear becomes necessary in approximately $10-20 \%$ of arthroplasty cups [3, 4]. PE wear in a well-fixed uncemented cup is often treated by exchanging the PE liner and femoral head [1]. Whether to revise a well-fixed and well-positioned acetabular component in the presence of PE wear and osteolysis remains controversial [1]. Choosing the best procedure for revision surgery in patients showing PE wear involves the difficult decision whether to revise only the liner (e.g. lipped liner, constrained liner, increasing femoral head size) and face a high risk of postoperative hip dislocation or to revise both the cup (e.g. reposition of the cup) and the liner and use a dual-mobility component to reduce the risk of hip dislocation [5]. 
The current literature reports considerable disagreement over the revision method preferred for revising worn-out liners. Previously published studies argue that leaving the well-fixed and well-positioned cup unchanged at revision diminishes the probability of postoperative dislocation [6-8], whereas other reports claim the opposite $[9,10]$. Some authors advocate acetabular cup revision, while others insist on cup preservation with exchange of the liner only $[6,11]$. Some studies have shown that leaving a well-fixed acetabular shell in situ may also lead to an increased risk of instability [12].

These considerations need to be balanced against the otherwise low complication rate for revision of the liner [12]. Replacement of a PE liner is considered more benign than full acetabular revision and a relatively simple procedure with less blood loss, shorter operation and hospitalization time [5]. Therefore, isolated exchange of the liner has become an increasingly common indication for revision surgery, even when facing a high rate of dislocation [9].

Among our patients we observed an unexpectedly high incidence of recurrent dislocation after liner exchange followed by revision of the cup. The purpose of this retrospective study was to determine the rate of THA dislocation following liner exchange.

\section{Materials and methods}

The study was approved by the local ethics committee (Medical University of Innsbruck, Austria). We retrospectively investigated all consecutive patients at our department who between January 2000 and December 2014 underwent isolated PE liner exchange for wear with retention of the acetabular cup and femoral stem. Patients were included if (1) the PE liner was removable, (2) the acetabular shell was stable with acceptable orientation, (3) no osteolysis around the acetabular cup was found, and (4) no dislocation of the THA occurred before revision surgery. Exclusion criteria were revision of either the acetabular or the femoral component at the same intervention or a diagnosis of infection.

We identified a total of 124 patients, 82 of whom fulfilled the inclusion criteria. We then divided our study population of 82 patients into two groups (a) liner exchange without postoperative THA dislocation (control group) and (b) liner exchange with postoperative THA dislocation (study group; Fig. 1). Patient flow chart is shown in Fig. 2.

We also investigated patient medical histories for sociodemographic data, surgical approach, cut to suture time, pre- and postoperative range of motion, Charlson Comorbidity Score [13], body mass index, femoral and acetabular offset, details of revision procedure and blood loss during surgery, Estimated blood loss was calculated using the formula of Meunier [14]. Each substitution of concentrated red blood cells, administered intra- or postoperatively until the fifth day, was included in the calculation with a quantity of $280 \mathrm{ml}(\mathrm{ml})$ and a haematocrit of 0.54 .

Prosthetic stability, PE wear and cup migration were retrospectively assessed with EBRA (German: Einzel-BildRöntgen-Analyse) [15] from plain $x$ rays. EBRA is a wellestablished method that evaluates standard anterior-posterior radiographs without requiring additional means at exposure (e.g., ball markers). Simulating the spatial situation, it computes parameters of longitudinal and transverse migration of prosthetic cup, femoral head and wear. The migration of the femoral head, the acetabular cup and wear in the horizontal and vertical directions can be studied. Total wear was calculated from the EBRA wear results in the horizontal and vertical directions by vectorial addition to make the results comparable with those of other methods. Furthermore, total wear was calculated as the differences between migration of the head and cup in the horizontal and vertical directions. A comparability algorithm using a

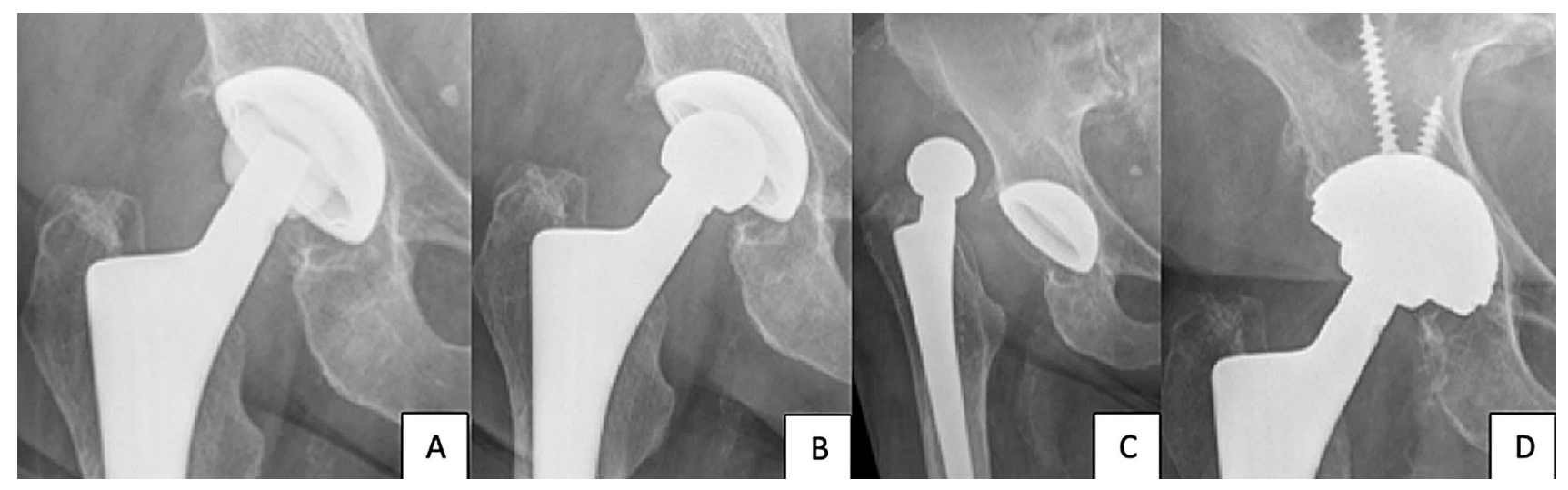

Fig. 1 Massiv PE liner wear a without osteolysis around the cup or the greater trochanter. Postoperative x-ray control after revision of the liner. b Dislocation after liner exchange. c Cup revision to a dual mobility liner and cup with additionally screw fixation 

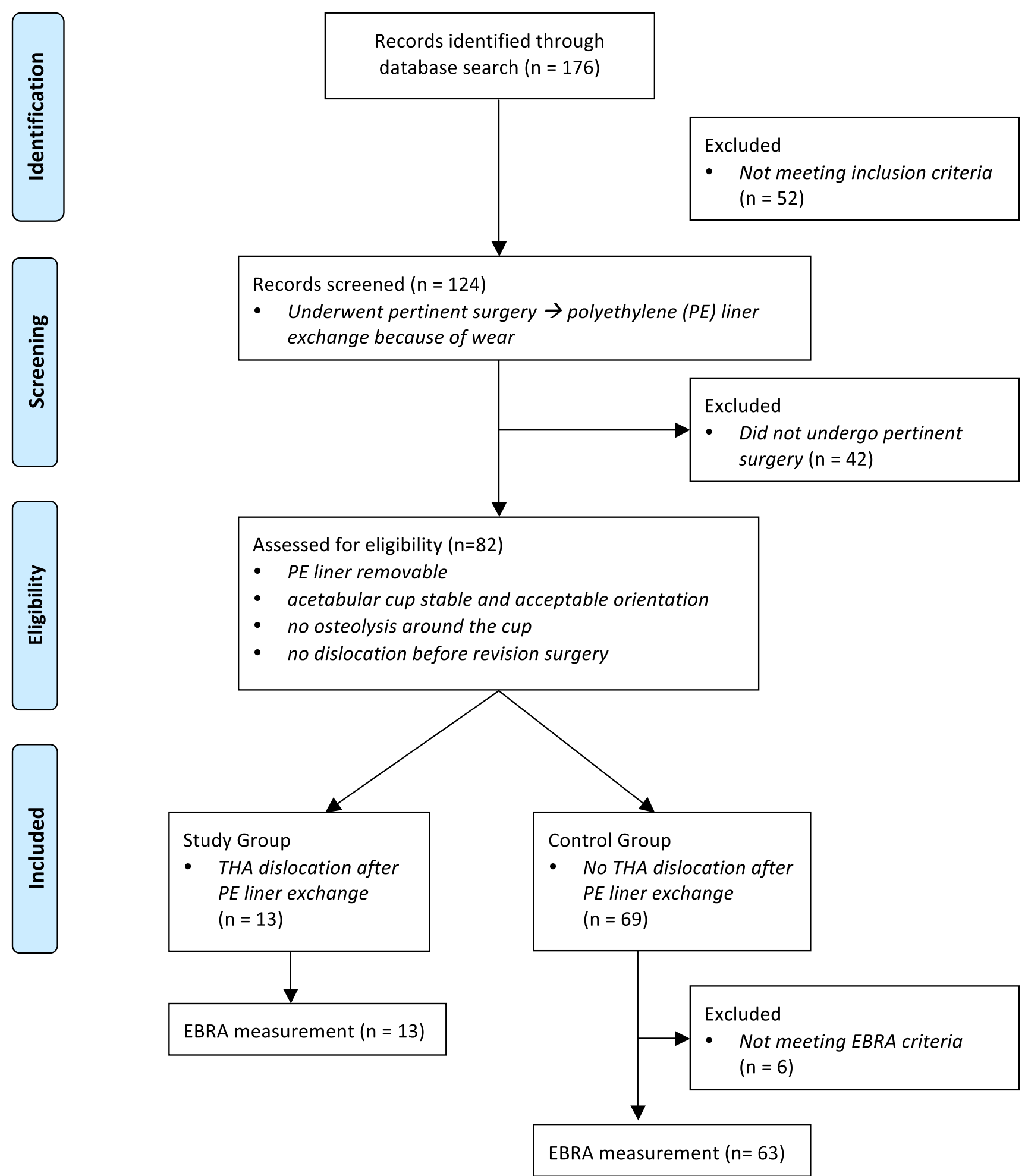

Fig. 2 PRISMA 2009 flow diagram detailing inclusion and exclusion of the patients

grid of transverse and longitudinal tangents of the pelvis contour divides serial radiographs into sets of comparable ones. Migration is measured only between comparable radiographs. The $95 \%$ confidence limits for EBRA results are
$1.0 \mathrm{~mm}$ for longitudinal and $0.8 \mathrm{~mm}$ for transverse migration [15].

In our department, we routinely follow patients with radiographs before discharge, 6 weeks after surgery and 
12 month postoperative. We perform additional radiographs if the patient has any complaints with the THA. All radiographs were taken at our Department of Radiology with the same technique (anterior-posterior (AP) radiographs; patient standing in upright position and full weight-bearing). For our EBRA investigation, a minimum of three radiographs per patient and a minimum radiological follow-up of up to 6 months was required for this analysis. Cup migration analysis was done with EBRA by one independent investigator, who was not involved in the surgeries or postoperative treatment of patients.

Additionally, to preoperatively rule out an infection, a preoperative fluoroscopy-guided joint fluid sample was gathered (study group: $n=8 / 13$; control group: $n=38 / 69$ ). In all cases no infection was found. Unfortunately, no further investigation was performed, e.g., histopathological diagnosis of the synovia for the identification of particles of prosthesis material or polyethylene particles. This would have been of great importance in the evaluation of implant failure. An additional comment will be added in the Limitations section.

\section{Statistical analysis}

Mean, median, range, and standard deviation were calculated for the various measurement parameters. For analysis, Access and Excel (Microsoft Office Professional Plus 2010, Redmond, US-WA) as well as Graph Pad Prism (Version 7.0, GraphPad Software, Inc., La Jolla, US-CA) were used. For pairwise comparison of various parameters the non-parametric Mann-Whitney $U$ test was used. Two-Way ANOVA with Sidak correction for multiple comparisons was used to assess statistical significance within migration, wear rates, inclination and anteversion. A $p$ value of 0.05 was considered statistically significant.

\section{Results}

The most important findings in our study were the high rate of THA dislocation and the unexpectedly high rate of cup revision after liner exchange in our study group. We found an absolute risk increase of $16 \%$ after revision surgery, which results in a number needed to harm of 6 . This means that every sixth patient with isolated liner exchange can expect to experience dislocation due to wear.

\section{Sociodemographics}

As mentioned above, we divided our study population into a study $(n=13)$ and a control $(n=69)$ group. The study group included 13 patients (10 female, 3 male) with a mean age of 70 (range: 46-83) years at PE liner exchange.
The control group consisted of 69 (37 female, 32 male) patients with a mean age of 67 (range: 26-83) years at time of revision surgery. No significant difference was found between the two groups for comorbidities following the Charlson Comorbidity Score [13] $(p=0.2)$. Details shown in Table 1.

\section{Implant survival and revision surgery indication}

In our study group $(n=13)$, revision surgery because of PE wear was necessary at a mean of 10.8 (range: 8.3-13.5) years after primary THA, while the control group $(n=69)$ underwent liner exchange after a mean of 9.5 (range: $0-16.7)$ years. No statistically significant difference in implant survival rates $(p=0.5)$ was found between the two groups. The indication for exchange of the liner in both groups was PE wear. In the study group, all 13 patients had a DePuy Synthes (DePuy-Synthes, Warsaw IN, USA) Duraloc ${ }^{\circledR}$ Marathon neutral liner inserted, while in the control group 44 patients received a DePuy Synthes (DePuy-Synthes, Warsaw IN, USA) Duraloc ${ }^{\circledR}$ Marathon liner (neutral) and 25 a Stryker (Stryker Howmedica Osteonics) Crossfire ${ }^{\circledR}$ liner (neutral). After revising the PE liner, an average of three (range: 1-6) THA dislocation occurred after a mean of 20.2 (range: 1-44) weeks postoperative. In the control group no postoperative dislocation occurred. All THA dislocations were repositioned under fluoroscopic guidance. After a mean of one (range: $0-2)$ years and recurrent THA dislocations six patients $(n=6 / 13)$ in the study group underwent cup replacement to a dual-mobility cup, three patients $(n=3 / 13)$ received a $10^{\circ}$ lipped liner and four patients $(n=4 / 13)$ a constrained liner. After the second revision surgery no dislocation was noticed in our patient reporting system in the investigated follow-up period.

\section{Surgical approach}

All patients in the study group $(n=13)$ were initially operated through a lateral-transgluteal approach [16]. At liner revision the approach was converted in 11 patients $(n=11 / 13)$ to a direct anterior approach (DAA) [17, 18], while in two patients $(n=2 / 13)$ the initial lateral-transgluteal approach was used. In the control group 12 patients $(n=12 / 69)$ were initially operated with a DAA and 43 patients $(n=43 / 69)$ with a lateral-transgluteal approach. Information on the surgical approach is missing in 14 cases $(n=14 / 69)$. Liner revision surgery was performed with a DAA in $54(n=54 / 69)$ cases, while in 14 patients $(n=14 / 69)$ the lateral-transgluteal approach was used. In one patient the approach for revision surgery was not recorded $(n=1 / 69)$. 
Table 1 Sociodemorgaphic data, EBRA cup measurement results, blood loss, surgical approach and used liner at the revision surgery

\begin{tabular}{|c|c|c|c|}
\hline & Study group & Control group & $p$ values \\
\hline Participants & 13 (f. 10; m 3) & 69 (f.37; m32) & n.s \\
\hline Age at revision surgery (yr) & $70(46-83)$ & $67(26-83)$ & n.s \\
\hline Body-mass index & $28(21.4-42.7)$ & $37.7(17.7-38.7)$ & n.s \\
\hline Charlson comorbidity Index & $2.8(0-7)$ & $3.7(0-13)$ & n.s \\
\hline \multicolumn{4}{|c|}{ Surgical approach inital surgery } \\
\hline Lateral & 13 & 43 & \\
\hline Direct anterior approach & 0 & 12 & \\
\hline Missing & 0 & 14 & \\
\hline \multicolumn{4}{|c|}{ Revision Surgery - Liner Exchange } \\
\hline \multicolumn{4}{|l|}{ Surgical approach by revision } \\
\hline Lateral & 2 & 14 & \\
\hline Direct anterior approach & 11 & 54 & \\
\hline Missing & 0 & 1 & \\
\hline Cut to suture time (min.) & $60( \pm 21)$ & $60( \pm 27)$ & n.s \\
\hline Blood loss in ml & $800( \pm 600)$ & $900( \pm 600)$ & n.s \\
\hline \multicolumn{4}{|l|}{ Used liner in revision } \\
\hline Neutral & 9 & 46 & \\
\hline $10^{\circ}$ lipped & 3 & 21 & \\
\hline Constrained & 1 & 0 & \\
\hline Missing & 0 & 2 & \\
\hline Radiological follow up (yr.) & $6(3.6-9.9)$ & $6(3.6-9.9)$ & n.s \\
\hline \multicolumn{4}{|l|}{ EBRA cup measurments } \\
\hline Medial migration (mm) & $3(-2-7.9)$ & $1.5(-2.6-1.6)$ & 0.032 \\
\hline Cranial migration (mm) & $2.6(-1.4-2.5)$ & $2(-1.8-28.9)$ & 0.001 \\
\hline Inclination & $45.5^{\circ}(25.4-56.7)$ & $44^{\circ}(33.2-55.9)$ & n.s \\
\hline Anterversion & $16.4^{\circ}(7.2-23.4)$ & $18.2^{\circ}(6.5-34.6)$ & n.s \\
\hline Wear (mm) & $0.3(0-3.7)$ & $0.15(-2.6-1.6)$ & n.s \\
\hline
\end{tabular}

$F$ female, $m$ male, $y r$ years, $\min$ minutes, $m m$ millimetre, $n . s$. not significant

\section{Head and Liner}

In the control group, PE liner revision surgery was performed in 46 patients $(n=46 / 69)$ with a neutral liner and in 21 patients $(n=21 / 69)$ with a $10^{\circ}$ lipped liner. Information on the used liner is missing in two patients $(n=2 / 69)$. In the study group, nine patients $(n=9 / 13)$ received a neutral liner, three patients $(n=3 / 13)$ a $10^{\circ}$ lipped PE liner and one patient $(n=1 / 13)$ a constrained liner. Head size was changed from $28 \mathrm{~mm}(\mathrm{~mm})$ to $32 \mathrm{~mm}$ in five patients $(n=5 / 13)$, in an additional five patients $(n=5 / 13)$ head size was not changed $(32 \mathrm{~mm})$ and in three patients ( $n=3 / 13)$ in the study group this information is missing. In the control group, head size was changed from 28 to $32 \mathrm{~mm}$ in 23 patients $(n=23 / 69)$, in 12 patients $(n=12 / 69)$ head size was not changed $(32 \mathrm{~mm})$ and in 34 patients $(n=34 / 69)$ this information is missing. Expect the missing data, in all other cases the head length was not changed during revision surgery.

\section{EBRA measurements}

Mean radiological follow-up was six (range: 3.6-9.9) years for both groups. All patients in the study group fulfilled the EBRA criteria, while six patients in the control group had to be excluded due to incomplete radiologic follow-up. EBRA analysis showed a significant difference between the two groups in medial $(p=0.032)$ and cranial cup migration $(p=0.001)$. Mean medial cup migration in the study group was $3 \mathrm{~mm}$ (range: -2 to 7.9 ), while in the control group $1.5 \mathrm{~mm}$ (range: -2.6 to 1.6 ). Mean cranial cup migration was $2 \mathrm{~mm}$ (range: -1.8 to 28.9 ) in the study group and $2.6 \mathrm{~mm}$ (range: -1.4 to 2.5 ) in the control group. Details are shown in Fig. 3. Wear measurements with EBRA did not show a statistically significant difference ( $p=0.968)$ between both groups. Mean total wear in the study group was $0.3 \mathrm{~mm}$ (range: $0-3.7$ ) and $0.15 \mathrm{~mm}$ (range: -2.6 to 1.6 ) in the control group. 

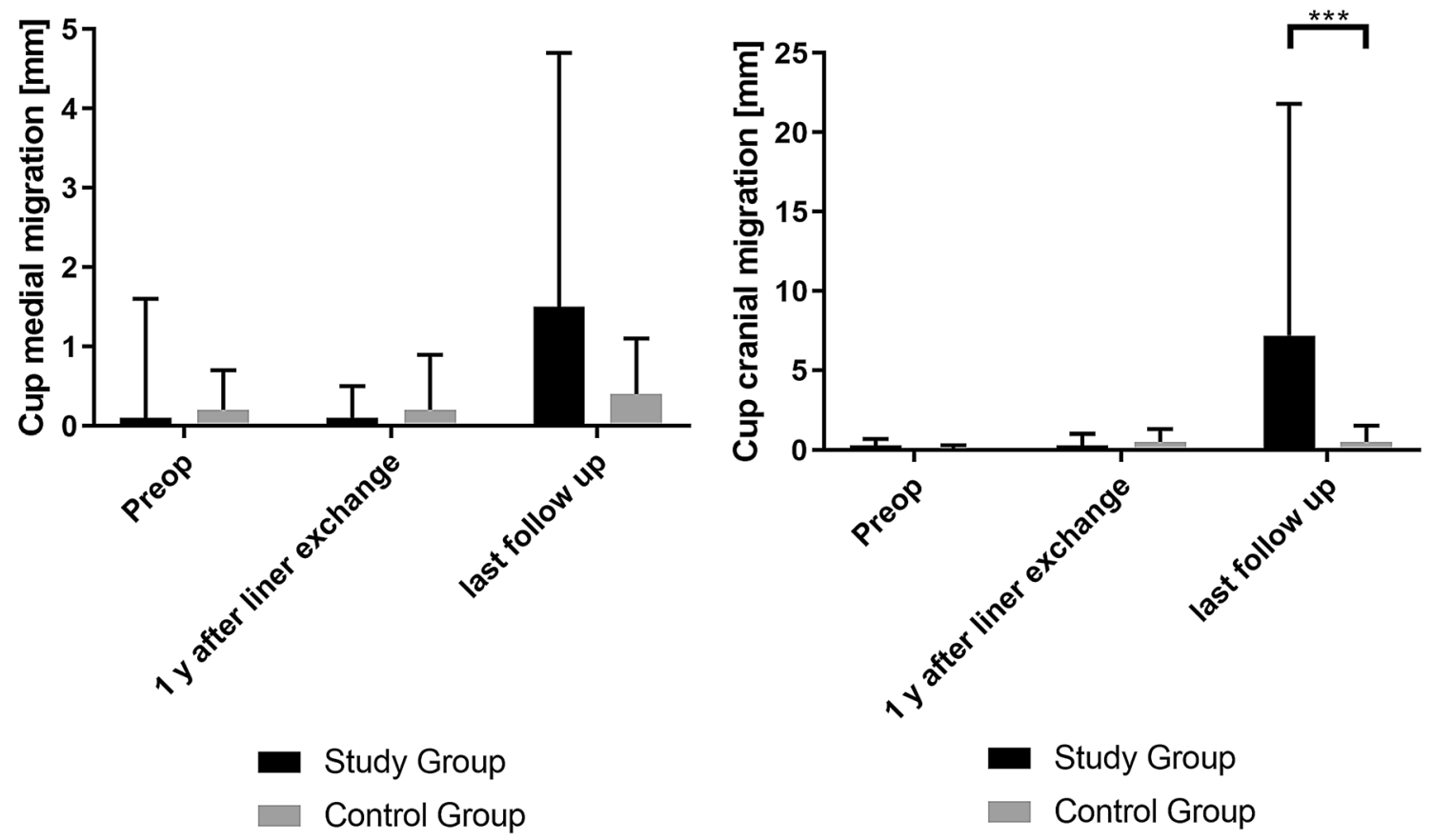

Fig. 3 Mean cup migration and standard deviation of EBRA-cup analysis. Medial and cranial cup migration in the study group at last follow-up after liner exchange was significantly increased

No significant difference was found for the cup inclination $(p=0.166)$ and anteversion $(p=0.234)$ between the two groups. Mean inclination in the study group was $45.5^{\circ}$ (range: $25.4^{\circ}-56.7^{\circ}$ ) and in the control group $44^{\circ}$ (range: $\left.33.2^{\circ}-55.9^{\circ}\right)$. Mean cup anteversion in the was $16.4^{\circ}$ (range: $7.2^{\circ}-23.4^{\circ}$ ) for the study group and $18.2^{\circ}$ (range: $6.5^{\circ}-34.6^{\circ}$ ) for the control group. In addition, no significant difference in postoperative femoral $(p=0.196)$ or acetabular offset was observed between the two groups $(p=0.702)$.

\section{Discussion}

The purpose of the present study was to determine the rate of THA dislocation after liner exchange because of PE wear in a well-fixed and orientated cup without osteolysis. The most important findings in our study were the high rate of THA dislocation and the unexpectedly high rate of cup revision after liner exchange in our study group.

According to the literature, treating polyethylene wear with isolated liner exchange in a well-fixed acetabular cup has become an increasingly common procedure in revision THA [7]. Changing the PE liner can limit morbidity and avoids bone loss associated with removal of a well-fixed cup $[7,19]$. The literature reports that the implant survival rate after liner replacement is comparable with that observed after more complex revisions, but that the risk of THA dislocation is significantly higher [19].
After revision total hip arthroplasty (rTHA), dislocation rates of up to $39 \%$ are reported [20] as compared to incidences ranging from $0.5 \%$ to $5 \%$ after primary THA [12, 21 , 22]. The source of this increase in dislocations after revision surgery is still not fully understood and appears to be multifactorial [23]. In our patient series the dislocation rate after $\mathrm{PE}$ liner exchange for wear was $15.8 \%$. This rate is consistent and well in line with previously published studies regarding rTHA because of PE wear [1, 5].

Several studies have shown that larger femoral head size directly influences stability [24, 25]. A recent study by Faldini et al. mentioned that it is advisable to use a $36-\mathrm{mm}$ head diameter or larger when performing rTHA [23]. In our study, the head size most commonly used for revision surgery was $32 \mathrm{~mm}$ in both groups. Unfortunately, there was insufficient data to analyze our results on head size.

To reduce the risk of dislocation after rTHA some authors advocate using an elevated rim liner; even though a poorly positioned and elevated rim liner can inadvertently result in impingement with the iliopsoas muscle or tendon, leading to anterior hip pain $[24,26]$. In addition, the study by Labek et al. demonstrated a very high failure rate for constrained liners [27]. With regard to dislocation rate, we found no advantage in using a $10^{\circ}$ lipped or constrained liner, but there was insufficient data to analyze our results considering the above-mentioned liners. Further investigation is needed.

The effect of age on the dislocation rate after rTHA is still the subject of controversy. Wetters et al. [25] found 
that younger patients have a greater risk of dislocation after rTHA. Jo et al. [28] found dislocation rates to have no significant age-dependency. Yoshimoto et al., on the other hand, identified advanced age as a significant independent risk factor for dislocation. In our study, the two groups showed no significant differences in age composition or comorbidity index. We, therefore, detected no influence of age or comorbidity on the probability of dislocation.

In a study by Kosashvili et al. dislocation rates in patients undergoing first-time revisions were found to be significantly lower than in those undergoing repeat revisions [24, 28-31]. Some authors suggest combining revision of the femoral and the acetabular side to achieve the best positioning and restoration of correct offset [24, 32]. A previously published study found dislocation rates for acetabulum-only revisions to be significantly higher than those for both components and femur-only reconstructions within the group of first-time revisions [24]. According to the literature, a reduction in rTHA dislocation can be achieved using dual-mobility cups [33-37]. The risk of dislocation seems to increase with every additional surgical procedure. In our study, we found dislocations when using lipped or constrained liners and when enlarging the head size. We found no difference related to the choice of surgical approach for primary THA of rTHA. Nevertheless, in $7.3 \%$ of our study population a revision of the cup in the observed follow-up period became necessary because of recurrent dislocations after liner exchange. Unfortunately, our data are too insufficient to show a statistically significant difference. Neverhteless, a trend can be seen and further investigation is needed.

To the best of our knowledge, we are the first study to date to investigate dislocation rate after liner exchange using EBRA measurements for wear and cup migration. A recently published study by Abrahams et al. reported accuracy of the EBRA cup in uncemented acetabular components [38]. In addition, for EBRA cup and radiostereometric analysis (RSA) the authors reported good agreement on classification of components that migrated proximally $1 \mathrm{~mm}$ up or down at two years with $100 \%$ sensitivity and $87 \%$ specificity [38]. In our study, EBRA analysis showed significantly greater medial and cranial cup migration in the study group. Secondary instability might have occurred after initial subsidence. This may be understood as an early sign of later aseptic loosening and a symptom of osteolytic weakening of the bone stock [39], but this investigation was not part of the present study.

Another very important issue for recurrent dislocations in patients with wear of the polyethylene liner is seen to be the pathophysiological mechanisms of PE wear. In recent studies the pathophysiological mechanisms of PE wear and PE wear-induced osteolysis have been studied extensively [40-42]. It has been shown that debris particles can induce a cellular response in periprosthetic tissues, with the up-regulation of toll-like receptors (TLRs) on macrophages [43, 44]. TLR signaling leads to up-regulation of many chemokines and cytokines, such as TNF- $\alpha$, IL- $1 \beta$, MCP1 and others $[43,44]$. The inflammatory response that ensues leads to activation of osteoclasts and induction of local bone resorption [43, 44]. Lachiewicz, Watters and Oral et al. showed improved wear resistance for new generation polyethylene, as highly X-linked polyethylene and vitamin E-doped polyethylene by comparison with conventional liners [43, 44]. Although the description above was not underlying our study results, the wear rate in the study group was twice as high as compared with that of the control group. This could be a weak indication that the PE particle concentration in the surrounding soft tissue have been higher and, therefore, weaken the tightness of the collagen fibers. Nevertheless, our study revealed no significant difference in PE wear in either group. Even though we found no statistical significance with regard to wear rate, but our study may provides further insights into potential risk factors and might add information to the recent debate on dislocation after rTHA, especially concerning cup migration.

The present study has several limitations, such as the retrospective methodology and the selection bias of the study group. Patient follow-up was not blinded or randomized, for which reason bias and confounders are difficult to rule out. Furthermore, we concentrated on measuring cup positioning with EBRA, but the technology does not allow femoral component rotation to be measured to calculate combined anteversion as an important risk factor for prosthetic impingement and dislocation. A preoperative fluoroscopy-guided joint fluid sample was gathered to rule out low-grade infection. Unfortunately, no further investigation was performed, e.g., histopathological diagnosis of the synovia for identification of particles of prosthesis material or polyethylene particles. This would have been of great importance in evaluating implant failure. In addition, we didn't perform a power analysis wether the number of patients has enough volume to compare; instead we calculated a numerative factor with increased risk in percent and the number needed to harm.

Our study shows that exchange of the PE liner for wear entails a high risk of dislocation and an unexpectedly high risk of cup revision. In $46 \%$ of our study group patients the cup was revised. It would seem that this risk is increased when PE wear is combined with cup migration, thus potentially leading to instability. Surgeons should address individual risks, e.g., using large head diameters, dualmobility cups, liners with elevated rim, and should stick to exact positioning, especially in patients with abductor deficiency. Further investigations are needed. 


\section{Conclusion}

In conclusion, isolated exchange of the polyethylene liner because of wear showed a high risk of dislocation and further cup revision. Further investigations are needed to assess if the threshold for revising well-fixed components in the case of liner wear should be lowered.

Author contributions All listed authors have substantially contributed to this study. All authors have reviewed and confirmed the accuracy of the whole manuscript.

Funding Open access funding provided by University of Innsbruck and Medical University of Innsbruck. This research did not receive any specific grant from funding agencies in the public, commercial, or not-for-profit sectors.

Availability of data and material Data will be sent if necessary.

Code availability Not applicable.

\section{Compliance with ethical standards}

Conflicts of interest The authors declare that they have no conflict of interest.

Ethics approval The local ethics committee approved the study protocol.

Consent to participateConsent to participate Not applicable. Retrospective study design.

Consent for publication All authors have reviewed and confirmed the accuracy of the whole manuscript.

Open Access This article is licensed under a Creative Commons Attribution 4.0 International License, which permits use, sharing, adaptation, distribution and reproduction in any medium or format, as long as you give appropriate credit to the original author(s) and the source, provide a link to the Creative Commons licence, and indicate if changes were made. The images or other third party material in this article are included in the article's Creative Commons licence, unless indicated otherwise in a credit line to the material. If material is not included in the article's Creative Commons licence and your intended use is not permitted by statutory regulation or exceeds the permitted use, you will need to obtain permission directly from the copyright holder. To view a copy of this licence, visit http://creativecommons.org/licenses/by/4.0/.

\section{References}

1. Petis SM, Kubista B, Hartzler RU, Abdel MP, Berry DJ (2019) Polyethylene liner and femoral head exchange in total hip arthroplasty: factors associated with long-term success and failure. J Bone Joint Surg Am 101:421-428. https://doi. org/10.2106/JBJS.18.00522

2. Adelani MA, Mall NA, Nyazee H, Clohisy JC, Barrack RL, Nunley RM (2014) Revision total hip arthroplasty with retained acetabular component. J Bone Joint Surg Am 96:1015-1020. https://doi.org/10.2106/JBJS.L.01177

3. Oberaigner WLH, Harrasser L, Krismer M, Blauth M (2015) Prothesenregister Tirol. Bericht über die Operationsjahre 20112013 und Revisionsstatistik der Operationsjahre 2004-2012. Innsbruck Tirol Kliniken Institut für klinische Epidemiologie

4. Grimberg A JV, Liebs T, Melsheim er O, Steinbrück A (2015) Endoprothesenregister Deutschland: Jahresbericht 2015. EPRD Deutsche Endoprothesenregister gGmbH Berlin

5. Koh KH, Moon YW, Lim SJ, Lee HI, Shim JW, Park YS (2011) Complete acetabular cup revision versus isolated liner exchange for polyethylene wear and osteolysis without loosening in cementless total hip arthroplasty. Arch Orthop Trauma Surg 131:1591-1600. https://doi.org/10.1007/s00402-011-1338-x

6. Wade FA, Rapuri VR, Parvizi J, Hozack WJ (2004) Isolated acetabular polyethylene exchange through the anterolateral approach. J Arthroplasty 19:498-500. https://doi.org/10.1016/j. arth.2004.02.005

7. O'Brien JJ, Burnett RS, McCalden RW, MacDonald SJ, Bourne $\mathrm{RB}$, Rorabeck CH (2004) Isolated liner exchange in revision total hip arthroplasty: clinical results using the direct lateral surgical approach. J Arthroplasty 19:414-423. https://doi.org/10.1016/j. arth.2004.02.001

8. Della Valle CJ, Shuaipaj T, Berger RA, Rosenberg AG, Shott S, Jacobs JJ, Galante JO (2005) Revision of the acetabular component without cement after total hip arthroplasty. A concise followup, at fifteen to nineteen years, of a previous report. J Bone Joint Surg Am 87:1795-1800. https://doi.org/10.2106/JBJS.D.01818

9. Boucher HR, Lynch C, Young AM, Engh CA Jr, Engh C Sr (2003) Dislocation after polyethylene liner exchange in total hip arthroplasty. J Arthroplasty 18:654-657. https://doi.org/10.1016/s0883 $-5403(03) 00266-3$

10. Beaule PE, Ebramzadeh E, Le Duff M, Prasad R, Amstutz HC (2004) Cementing a liner into a stable cementless acetabular shell: the double-socket technique. J Bone Joint Surg Am 86:929-934. https://doi.org/10.2106/00004623-200405000-00007

11. Lie SA, Hallan G, Furnes O, Havelin LI, Engesaeter LB (2007) Isolated acetabular liner exchange compared with complete acetabular component revision in revision of primary uncemented acetabular components: a study of 1649 revisions from the Norwegian Arthroplasty Register. J Bone Joint Surg Br 89:591-594. https://doi.org/10.1302/0301-620X.89B5.18623

12. Blom AW, Astle L, Loveridge J, Learmonth ID (2005) Revision of an acetabular liner has a high risk of dislocation. J Bone Joint Surg Br 87:1636-1638. https://doi.org/10.1302/0301-620X.87B12 .16349

13. Charlson M, Szatrowski TP, Peterson J, Gold J (1994) Validation of a combined comorbidity index. J Clin Epidemiol 47:12451251. https://doi.org/10.1016/0895-4356(94)90129-5

14. Meunier A, Petersson A, Good L, Berlin G (2008) Validation of a haemoglobin dilution method for estimation of blood loss. Vox Sang 95:120-124. https://doi.org/10.111 1/j.1423-0410.2008.01071.x

15. Krismer M, Bauer R, Tschupik J, Mayrhofer P (1995) EBRA: a method to measure migration of acetabular components. J Biomech 28:1225-1236

16. Bauer R, Kerschbaumer F, Poisel S, Oberthaler W (1979) The transgluteal approach to the hip joint. Arch Orthop Trauma Surg 95:47-49. https://doi.org/10.1007/bf00379169

17. Rachbauer F (2005) Minimally invasive total hip arthroplasty via direct anterior approach. Orthopade. https://doi.org/10.1007/ s00132-005-0854-1

18. Meermans G, Konan S, Das R, Volpin A, Haddad FS (2017) The direct anterior approach in total hip arthroplasty: a systematic review of the literature. Bone Joint J 99B:732-740. https://doi. org/10.1302/0301-620X.99B6.38053 
19. Bidar R, Girard J, May O, Pinoit Y, Laffargue P, Migaud H (2007) Polyethylene liner replacement: behavior and morbidity in 68 cases. Rev Chir Orthop Reparatrice Appar Mot 93:461-468. https ://doi.org/10.1016/s0035-1040(07)90328-1

20. Daly PJ, Morrey BF (1992) Operative correction of an unstable total hip arthroplasty. J Bone Joint Surg Am 74:1334-1343

21. Biedermann R, Tonin A, Krismer M, Rachbauer F, Eibl G, Stockl B (2005) Reducing the risk of dislocation after total hip arthroplasty: the effect of orientation of the acetabular component. J Bone Joint Surg Br 87:762-769. https://doi. org/10.1302/0301-620X.87B6.14745

22. Barrack RL (2003) Dislocation after total hip arthroplasty: implant design and orientation. J Am Acad Orthop Surg 11:89-99. https:// doi.org/10.5435/00124635-200303000-00003

23. Faldini C, Stefanini N, Fenga D, Neonakis EM, Perna F, Mazzotti A, Pilla F, Triantafyllopoulos IK, Traina F (2018) How to prevent dislocation after revision total hip arthroplasty: a systematic review of the risk factors and a focus on treatment options. J Orthop Traumatol 19:17. https://doi.org/10.1186/s1019 5-018-0510-2

24. Kosashvili Y, Backstein D, Safir O, Lakstein D, Gross AE (2011) Dislocation and infection after revision total hip arthroplasty: comparison between the first and multiply revised total hip arthroplasty. J Arthroplasty 26:1170-1175. https://doi.org/10.1016/j. arth.2011.04.022

25. Wetters NG, Murray TG, Moric M, Sporer SM, Paprosky WG, Della Valle CJ (2013) Risk factors for dislocation after revision total hip arthroplasty. Clin Orthop Relat Res 471:410-416. https ://doi.org/10.1007/s11999-012-2561-7

26. Alberton GM, High WA, Morrey BF (2002) Dislocation after revision total hip arthroplasty : an analysis of risk factors and treatment options. J Bone Joint Surg Am 84:1788-1792

27. Labek G, Brabec E, Frischhut S, Krismer M (2009) High failure rate of the Duraloc Constrained Inlay. Acta Orthop 80:545-547. https://doi.org/10.3109/17453670903316819

28. Jo S, Jimenez Almonte JH, Sierra RJ (2015) The Cumulative Risk of Re-dislocation After Revision THA Performed for Instability Increases Close to 35\% at 15years. J Arthroplasty 30:1177-1182. https://doi.org/10.1016/j.arth.2015.02.001

29. Springer BD, Fehring TK, Griffin WL, Odum SM, Masonis JL (2009) Why revision total hip arthroplasty fails. Clin Orthop Relat Res 467:166-173. https://doi.org/10.1007/s11999-008-0566-z

30. Khatod M, Barber T, Paxton E, Namba R, Fithian D (2006) An analysis of the risk of hip dislocation with a contemporary total joint registry. Clin Orthop Relat Res 447:19-23. https://doi. org/10.1097/01.blo.0000218752.22613.78

31. Cogan A, Klouche S, Mamoudy P, Sariali E (2011) Total hip arthroplasty dislocation rate following isolated cup revision using Hueter's direct anterior approach on a fracture table. Orthop Traumatol Surg Res 97:501-505. https://doi.org/10.1016/j. otsr.2011.04.005

32. Stedman RC, Lim D, Husain A, Courtney PM, Nelson CL (2016) Single-component revisions are associated with dislocation after revision total hip arthroplasty at intermediate-term follow-up. Hip Int 26:233-236. https://doi.org/10.5301/hipint.5000332
33. Langlais FL, Ropars M, Gaucher F, Musset T, Chaix O (2008) Dual mobility cemented cups have low dislocation rates in THA revisions. Clin Orthop Relat Res 466:389-395. https://doi. org/10.1007/s11999-007-0047-9

34. Philippot R, Adam P, Reckhaus M, Delangle F, Verdot F, Curvale G, Farizon F (2009) Prevention of dislocation in total hip revision surgery using a dual mobility design. Orthop Traumatol Surg Res 95:407-413. https://doi.org/10.1016/j.otsr.2009.04.016

35. Mertl P, Combes A, Leiber-Wackenheim F, Fessy MH, Girard J, Migaud H (2012) Recurrence of dislocation following total hip arthroplasty revision using dual mobility cups was rare in 180 hips followed over 7 years. HSS J 8:251-256. https://doi.org/10.1007/ s11420-012-9301-0

36. Civinini R, Carulli C, Matassi F, Nistri L, Innocenti M (2012) A dual-mobility cup reduces risk of dislocation in isolated acetabular revisions. Clin Orthop Relat Res 470:3542-3548. https://doi. org/10.1007/s11999-012-2428-y

37. Carulli C, Macera A, Matassi F, Civinini R, Innocenti M (2016) The use of a dual mobility cup in the management of recurrent dislocations of hip hemiarthroplasty. J Orthop Traumatol 17:131136. https://doi.org/10.1007/s10195-015-0365-8

38. Abrahams JM, Callary SA, Jang SW, Hewitt J, Howie DW, Solomon LB (2020) Accuracy of EBRA-cup measurements after reconstruction of severe acetabular defects at revision THR. J Orthop Re. https://doi.org/10.1002/jor.24623

39. Krismer M, Stock1 B, Fischer M, Bauer R, Mayrhofer P, Ogon M (1996) Early migration predicts late aseptic failure of hip sockets. J Bone Joint Surg Br 78:422-426

40. Harris WH (1995) The problem is osteolysis. Clin Orthop Relat Res 311:46-53

41. Mall NA, Nunley RM, Zhu JJ, Maloney WJ, Barrack RL, Clohisy JC (2011) The incidence of acetabular osteolysis in young patients with conventional versus highly crosslinked polyethylene. Clin Orthop Relat Res 469:372-381. https://doi.org/10.1007/s1199 9-010-1518-y

42. Broomfield JA, Malak TT, Thomas GE, Palmer AJ, Taylor A, Glyn-Jones S (2017) The Relationship between polyethylene wear and periprosthetic osteolysis in total hip arthroplasty at 12 years in a randomized controlled trial cohort. J Arthroplasty 32:11861191. https://doi.org/10.1016/j.arth.2016.10.037

43. Lachiewicz PF, Watters TS (2016) The jumbo acetabular component for acetabular revision: Curtain Calls and Caveats. Bone Joint J 98B:64-67. https://doi.org/10.1302/0301-620X.98B1.36139

44. Oral E, Christensen SD, Malhi AS, Wannomae KK, Muratoglu OK (2006) Wear resistance and mechanical properties of highly cross-linked, ultrahigh-molecular weight polyethylene doped with vitamin E. J Arthroplasty 21:580-591. https://doi.org/10.1016/j. arth.2005.07.009

Publisher's Note Springer Nature remains neutral with regard to jurisdictional claims in published maps and institutional affiliations. 